\title{
trabalhonecessário
}

issn: $1808-799 \mathrm{X}$

ano 3 número $3-2005$

\section{O SINE COMO LUGAR DO CUIDADO}

\section{Simone Valdete dos Santos[i]}

A Convenção 88 da Organização Internacional do Trabalho (OIT), datada de 1950, recomendava a organização de Sistemas Públicos de Emprego nos países. No Brasil o SINE (Sistema Nacional de Emprego) foi criado em 1975, ratificado pela Constituição de 1988 com agências organizadas pelos Estados da União com a incumbência de intermediar postos de trabalho, organizar programas de qualificação profissional, encaminhar recebimento de seguro-desemprego, providenciar a confecção de carteiras de trabalho, entre outros programas de geração de emprego, trabalho e renda definidos regionalmente. A pesquisa de Doutorado realizada no município de Pelotas, com recursos da Fundação de Amparo à Pesquisa do Rio Grande do Sul (FAPERGS), cujo levantamento empírico ocorreu durante o ano de 2002, intitulada "O Ser e o Estar de Luto na Luta:

Educação Profissional em tempos de desordem" identificou a agência do Sistema Nacional de Empregos (SINE) enquanto um espaço privilegiado de passagem dos desempregados.

A metodologia qualitativa implementada foi de caráter etnográfico, constando registros em diários de campo das observações realizadas[ii] durante o expediente de trabalho na agência do SINE de Pelotas.

As impressões dos desempregados, após sua passagem pela intermediação de emprego, realizando um cadastro como candidato à vaga de emprego no SIGAE (Sistema Informatizado de Gerenciamento na Área de Emprego), não variam muito do entendimento dos funcionários do SINE sobre suas rotinas: 
“-O 'moreno[iii]' aquele da portaria, bem simpático, disse para mim não ir tão cedo das próximas vezes ao SINE, a vaga de emprego fica lá, e a agência só abre às 8 horas" (Esse candidato chegou às 6 horas).

“- Acho o 'moreno' da portaria simpático, tem funcionárias que se esforçam em ver alguma coisa no computador para gente, outras não."

“-Fiz ficha no SINE, fui atendido por uma moça que me deu 'dicas' para conseguir ocupação de motorista".

“- Antes de prestar concurso na prefeitura, fiz ficha no SINE me olharam mal, acho que em função da minha idade, estava com 40 anos".

"- Acho o pessoal do SINE apático, frio no tratamento das pessoas, no empenho para conseguir alguma coisa para o desempregado".

A simpatia do "moreno" da portaria compõe um lugar de cuidado das pessoas que passam pelo SINE, sendo simpatia um dos integrantes da ética do cuidado teorizada por Nörnberg da Silva (2002):

Como um sentimento constitutivo da ética do cuidado, a simpatia também se aproxima à compaixão. Partindo da idéia de que simpatia é o ato de sentir inclinação, ou seja, é o processo de atração, de re-ligação que ocorre entre uma pessoa e outra, a compaixão desperta em cada um o pesar, a dor que o outro sente. Ter com-paixão, compadecer-se, é ter um sentimento profundo que torna a pessoa capaz de sentir o sofrimento do outro em seu próprio corpo, sobrepondo-se à lucidez e à razão. É viver e sentir a dor do outro em seu próprio corpo, em seu coração, em suas entranhas (p.48, grifos da autora).

A recepção do SINE, pelo que observei e também pelo depoimento do atual recepcionista e da telefonista que já trabalhou na recepção, é um lugar, como bem coloca Nörnberg da Silva, no qual se vive e sente a dor do outro em seu próprio corpo, em seu coração, em suas entranhas:

"O recepcionista do SINE atendia várias pessoas, sendo as fichas que distribuía: azul para cadastro com carteira de trabalho; vermelha para seguro-desemprego, FGTS e para os pescadores, que pelo trabalho sazonal, recebem seguro-desemprego; verde para retorno, para ver no sistema se tem alguma vaga com carteira profissional; amarela confecção da carteira profissional. Falou que seu trabalho é de pára-choque, que as pessoas que ali chegam estão na UTI, que em seus 13 anos de trabalho no SINE sempre gostou de ficar na recepção. A telefonista do SINE me disse que não tem preparo psicológico para ficar na recepção, é muito desgastante, já ficou, mas pediu para sair, o funcionário que está de recepcionista, segundo ela, é ótimo. A recepção, segundo ela, é uma parabólica -capta

tudo. O funcionário mais antigo da agência lhe dava uma força na época em que estava na recepção, somatizava muito, ficava doente de ficar ouvindo o pessoal. Uma vez uma moça chorou por ter vindo a pé do Capão do Leão[iv] e não ter conseguido nenhum emprego. (Diário de Campo, visita ao SINE em 13 de junho de 2002)"

Sentia no corpo a dor dos outros: somatizava tudo; como pára-choque amaciava os impactos, os afetos do outro, sendo afetado por ele; reconhecer seu papel como 
Unidade de Tratamento Intensivo, ou seja, de fato cuidar, tratar alguém que na sua opinião, para alguém que, é funcionário público e está na lógica do trabalho assalariado está muito "doente".

Atração, re-ligação referida por Nörnberg da Silva, no SINE a recepção é uma antena parabólica: capta tudo, ou seja, atrai tudo, re-liga tudo.

Em um outro momento o recepcionista falou que: “- Administramos um manicômio, é só seguro-desemprego em cima de seguro-desemprego".

Reportando novamente à obra de Nörnberg da Silva: “...sentir o sofrimento do outro em seu próprio corpo, sobrepondo-se à lucidez e à razão". Conceder seguro desemprego a todo momento para as pessoas, é opor-se a lucidez, à razão do emprego e todo contexto social que ele representa.

Nos dias em que convivi no interior do SINE, junto da recepção, observei que as pessoas que vinham encaminhar o seguro-desemprego e o recebimento do Fundo de Garantia por Tempo de Serviço, na sua maioria, se dirigiam a mesa do recepcionista de óculos escuros, falavam baixo e com a cabeça abaixada, alguns gaguejavam. O recepcionista, muitas vezes, precisou levantar de sua cadeira, ficar da altura das pessoas para ouvi-las.

Conforme o recepcionista, era comum aqueles que vinham encaminhar o segurodesemprego esquecerem seus documentos pessoais na agência: carteira de trabalho, carteira de identidade. Percebi um sentimento de humilhação dessas pessoas que já possuíram carteira assinada e, naquele momento, estavam desempregadas.

Considero tais atitudes das pessoas desempregadas recentemente, em esconder o rosto, falar baixo, esquecer documentos significativos, como a carteira de trabalho, a manifestação do luto da carteira assinada. Estar no SINE era um momento de pesar, formalizavam mais uma vez o fato de estarem sem emprego.

A atitude do recepcionista era sempre a mesma: muita delicadeza, sua voz tem um timbre alto, claro. Para a confecção da carteira de trabalho conduzia a pessoa até a porta, mostrava a agência do Banco do Brasil, na outra quadra, onde era para pagar uma taxa. 
Um comportamento profissional de profundo cuidado com as pessoas, consciente de sua responsabilidade em evitar os choques, conviver com quem estava na UTI, administrar um manicômio.

Desde o início do levantamento de dados, quando a sede do Centro Regional de Desenvolvimento, Trabalho e Renda e a agência do SINE de Pelotas ficavam em um prédio alugado, até o prédio reformado da antiga exatoria federal da cidade como sede definitiva, me chamou atenção a bela apresentação do "pára-raio", "antena parabólica”: o recepcionista todas as vezes[v] estava bem vestido, atendendo pontualmente, não fazendo as pessoas esperar muito tempo na fila, agilizando o processo questionando os colegas dos "boxes" sobre quantas pessoas estavam atendendo, se havia possibilidade de mais fichas quando havia muita fila na rua, pois distribuía as fichas para as pessoas, explicava a demora no atendimento, pedia que voltassem mais tarde aqueles que tivessem "alguma volta" para dar no centro da cidade.

O recepcionista me contou que, no início da gestão estadual de Olívio Dutra, assumiu a captação de vagas, mas não gostou, voltou para a portaria, pois sendo pára-choque ameniza o choque para os colegas. Nunca foi grosseiro com ninguém, segura a barra de alguém que está "explodindo". Recordou que um dia, tinha um senhor cabisbaixo perto dele. Ao final do expediente da manhã, falou para o senhor que tinha que fechar a agência para o almoço. O homem chorou e contou que não tinha conseguido nada de emprego, e a família estava sem o que comer em casa. Ele então pegou um ticket refeição que valia $R \$$ 6,00 e disse: “- Leva para casa e compra arroz e uma perna de lingüiça para teus filhos”.

Passou mais de um ano e, um dia, aparece o homem lá com uma caixa de marmelada para ele do emprego que estava naquele momento - gostou muito, se sentiu muito alegre de ver que o homem que ajudou estava bem.

Nesse relato do recepcionista, é possível identificar mais uma evidência da ética do cuidado, além da simpatia, conforme a obra de Nörnberg da Silva (2002) : a caridade.

"Pelotas é o centro da região sul e quem está ali, está além dos desesperados, sem dinheiro. Cansei de ver carteiras de trabalho que a pessoa nunca vai conseguir vaga do SINE em função da idade, da baixa escolaridade e tenho que ainda abrir um sorriso, 
passar a ficha e consolar a pessoa, mentir para ela e dizer que alguma coisa ela vai

encontrar. Pessoas que viviam de faxineiras, cortadores de grama, sendo que hoje há empresas específicas de limpeza e zeladoria que fazem este serviço. (grifos meus na escrita do diário de campo)"

O recepcionista reconhece os problemas estruturais da cidade para não existência de postos de trabalho, mas se coloca na tarefa de consolar, de aplicar uma mentira, nesse caso, como bem formula Balandier (1997b) uma mentira social, pois para o senhor que the trouxe a marmelada, o consolo, a atitude caridosa foi um estímulo, conseguiu um emprego e, no gesto de trazer a marmelada, Ihe devolveu muito mais do que seus $\mathrm{R} \$ 6,00$.

Há ética do cuidado quando colocamos em alerta e ação os sentidos, sejam os receptores à distância (audição e visão), sejam os receptores de proximidade (olfato, paladar e tato), bem como toda a capacidade de emocionar-se (os sentimentos). Esse modo de entender apresenta o caráter aberto, flexível e transitório sobre o qual construímos o modo de educar e cuidar, o modo de fazer as políticas públicas e, principalmente, o modo de gerir os espaços de interação humana e a própria rel-ação (Nörnberg da Silva, 2002, p.54).

Por certo, os sentidos do recepcionista estavam sempre alertas, desde a forma que se vestia, se preparando para a função, antecipando o cuidado, tocando as pessoas com uma bela apresentação, com um sorriso, falava piadas, principalmente para os homens, comentários engraçados para deixar as pessoas mais à vontade, mentiras sociais[vi] bem aplicadas compondo "quase verdades."

Certa vez, chegou um homem com um formulário em branco para recebimento do FGTS, não havia ainda preenchido o formulário, necessitando fazê-lo para poder receber. Ele levantou, tocou no braço do sujeito, foi até a porta e indicou a galeria próxima da praça da caixa d'água, para que preenchessem o formulário para ele. Depois que ele atendeu a imensa fila, questionei sobre o fato, achava que o homem não tinha dinheiro, ao que aparentemente parecia, para pagar pelo serviço do escritório da galeria, respondeu que eram amigos dele que trabalhavam na galeria "gente fina", que o homem, dizendo que ele mandara, teria seu formulário do Fundo de Garantia por Tempo de Serviço preenchido de graça, pois eram seus amigos.

[ . . . ]destacam-se como elementos constitutivos para o entendimento da ética do cuidado, o amor ou a caridade, a simpatia ou a compaixão, o toque e a felicidade. Estes são entendidos como estruturas fundamentais e constitutivas da ética do cuidado. (Nörnberg da Silva, 2002, p.55)

O espaço da recepção do SINE estava embebido, envolto, encharcado pela ética do cuidado: simpatia, caridade e toque como opção de ofício do funcionário que já tinha trabalhado na intermediação e não tinha gostado. Era sua opção desempenhar seu papel 
de cuidado na recepção. Os colegas reconheciam seu valor, nas palavras da telefonista, que já experimentara a função: ele é ótimo, sendo a recepção um lugar difícil conforme outra funcionária, com 24 anos e meio de atuação no SINE:

“ Já trabalhei na captação de vagas, na intermediação, de recepcionista que no início não gostava e aprendi a gostar, o único setor que não trabalhei foi o seguro-desemprego, porque o funcionário tem que ter uma senha para entrar no sistema, alguns colegas já têm

e também no $1^{\circ}$ Emprego. Antes me sentia menor que os colegas por não ter curso superior, mas comecei a perceber que, observando colegas mais antigos se aprende tudo, tenho facilidade para aprender, superei o sentimento de inferioridade".

Essa funcionária, a telefonista e o atual recepcionista têm em comum o máximo de escolarização no Ensino Médio, sendo a função da recepção considerada menor na organização do SINE, das pessoas que prestam concurso, pois não ocorre exigência por curso superior. Os resultados da pesquisa, no entanto, revelam o quanto a sabedoria da ética do cuidado, pelo recepcionista atual, fazem a diferença.

\section{Os cenários do cotidiano no SINE}

"- A coordenacão quer o pelo menos, não incentiva. Pela qualidade, experiência do grupo com políticas públicas, poderíamos ajudar a planejar. O outro coordenador realizava reuniões de planejamento com a gente. (Depoimento de funcionário em uma das visitas ao SINE, grifos meus no registro)"

A ausência de reuniões de planejamento era reclamação recorrente entre os funcionários, nos diversos setores do Centro Regional. O pelo menos, presente no depoimento, corresponde ao "pelo menos" que exige a função, o cumprimento das tarefas, sem maiores envolvimentos com os resultados. Ocorria fragmentação nas ações, privilégio à intermediação de emprego no preenchimento do cadastro no sistema, muitas vezes frio, apático, conforme depoimento de um desempregado.

O coordenador adjunto realizava reuniões de planejamento e possuía um informativo com as atividades desenvolvidas por todos setores do centro regional. $O$ coordenador que o substituiu extinguiu o informativo e o substituiu pela exposição das informações referentes aos setores no mural.

Na entrevista realizada com o coordenador regional titular, as informações sobre o número de funcionários na coordenadoria: três pessoas no Departamento de Assistência Social; duas funcionárias no Conselho da Mulher - instituído pela gestão de Olívio Dutra; na captação de vagas três pessoas; na intermediação de emprego seis pessoas; uma responsável pelo programa do artesanato gaúcho; duas funcionárias responsáveis pelo programa $1^{\circ}$ Emprego[vii], estágios com instituições do Estado, sobretudo Banrisul e CEEE (Companhia Estadual de Energia Elétrica) e demandas do Centro do Trabalhador 
Autônomo; uma pessoa na Central Telefônica; um funcionário na recepção; um funcionário gerente de manutenção dos três andares do prédio; um motorista do carro oficial da coordenadoria; duas funcionárias na secretaria do SINE; um funcionário para portaria e segurança; dois funcionários no Qualificar e secretaria da coordenação regional; uma funcionária coordenando as atividades junto à Fundação do Bem- Estar do Menor; a equipe da Economia Popular e Solidária do convênio com a UCPel; e o pessoal do SEDAI que estava se instalando para coordenação da Instituição Comunitária de Crédito Regional desde maio de 2002, coordenada pelo presidente do Sindicato da Alimentação, envolvendo também representação da Secretaria de Desenvolvimento Econômico e da Coordenadoria Regional de Desenvolvimento, Trabalho e Renda.

O governo Olívio Dutra no Estado, conforme depoimentos dos funcionários, primou por instalações adequadas das agências do SINE, prédios com instalações permanentes para os Centros Regionais de Desenvolvimento, Trabalho e Renda. Há inclusive uma rampa na entrada do SINE para os cadeiristas. Nos governos anteriores, ficavam em prédios alugados em condições precárias.

O governo estadual em 2002 entrou em contato com a Secretaria Municipal de Desenvolvimento Econômico e, a partir de um acordo, reformaram o antigo prédio histórico da exatoria estadual localizado no centro da cidade. $O 2^{\circ}$ andar ficou para a secretaria municipal, o térreo e o $1^{\circ}$ andar para a intermediação de emprego, Qualificar, microcrédito, economia popular e solidária[viii], DAS (Departamento de Assistência Social), entre outros setores vinculados ao centro regional. A idéia de vincular a Secretaria de Desenvolvimento Econômico ao Centro Regional de Desenvolvimento, Trabalho e Renda teve o caráter de otimizar os recursos públicos e integrar atividades, a despeito do programa estadual de geração de trabalho e renda - Coletivos de Trabalho que a secretaria acompanhava.

De fato, ocorreu integração entre a Centro Regional de Desenvolvimento, Trabalho e Renda e a Secretaria de Desenvolvimento Econômico, além do acompanhamento aos Coletivos de Trabalho, na implementação da Instituição Comunitária de Crédito, nas feiras populares[ix]. Considero como fatores que favoreceram a integração, além da proximidade do local, salas de trabalho próximas, também uma sintonia política e de afinidades pessoais dos gestores, pessoas que se entendiam bem, eram amigos.

Na concepção do governo estadual, o espaço do centro regional deveria priorizar políticas para o desenvolvimento, trabalho e renda, retirando emprego da nomeação dos 18 centros, localizados em cidades denominadas "pólo" no Estado. Os Centros de Regionais de Desenvolvimento, Trabalho e Renda (CRDTR) possuíam vinculação com a Secretaria Estadual do Trabalho, Cidadania e Assistência Social (STCAS) e Secretaria Estadual de Desenvolvimento e Assuntos Internacionais (SEDAI). A gestão Olívio Dutra "designou" as cem agências do SINE existentes no Estado como "Casa do Trabalhador". (Coloco que o 
governo estadual "designou" porque não se tornou uma denominação comum, pois entre os funcionários e desempregados, o termo "SINE" prevaleceu).

O termo "emprego" foi retirado da denominação das anteriores Coordenadorias Regionais de Emprego, Trabalho e Renda, para então os Centros Regionais de Desenvolvimento, Trabalho e Renda. Mas, no cotidiano dos funcionários, o "emprego" estava muito presente, tanto na sua ausência, com um número expressivo de pessoas desempregadas no cadastro, fila diária na porta da agência, quanto na sua presença, na medida em que as vagas acumuladas no setor de captação de vagas não eram preenchidas.

Conforme dados fornecidos pelos funcionários do SINE de Pelotas, a partir do SIGAE (Sistema Informatizado de Gerenciamento na Área de Emprego) não são poucas as pessoas que passam pela agência mensalmente.

Durante o mês de setembro de 2002, período de levantamento de dados da pesquisa, foram atendidas 3.965 pessoas, ocorrendo encaminhamento de 532 pessoas às vagas disponíveis de emprego no período. Colocados nas vagas, ou seja, efetivamente foram empregados 82 pessoas. No total foram 597 vagas captadas pela agência, ocorrendo um número inferior de candidatos encaminhados e ainda um número inferior de colocados nessas vagas.

A funcionária do SINE, responsável pelos encaminhamentos, falou que elas realizam uma checagem, telefonam para a empresa, a fim de esclarecer se a pessoa encaminhada foi efetivamente empregada. Logo, esse dado é confiável. O número de pessoas que retornaram ao posto para verificar sua situação no cadastro é 2.802 , e de requisições do seguro-desemprego, 609.

No mês de novembro de 2002 foram 247 vagas captadas, com um encaminhamento mais significativo: 571 candidatos, 14 colocações, 230 requisições de seguro-desemprego, 1.272 pessoas retornaram ao posto para checar se havia alguma vaga para sua situação, um total de 1.745 atendimentos. No mês de novembro a captação não ficou superior aos encaminhamentos como no mês de setembro, mas o número de efetivos empregos é desalentador: 14.

No mês de outubro, situação intermediária entre setembro e novembro já relatados, foram 209 vagas para 135 colocações, 4.287 atendimentos, sendo que 3.223 pessoas retornaram para ver sua situação no sistema, e 684 encaminharam o seguro-desemprego.

No mês de março, foram 225 vagas captadas, 473 encaminhamentos e 184 colocações, 907 requisições do seguro-desemprego.

De março a novembro o cadastro teve um crescimento considerável: de 10.472 
trabalhadores no cadastro em março para 19.488 em novembro. Conforme expressão do recepcionista do SINE, quase 20.000 pessoas de Pelotas e região na "UTI", sem nenhuma perspectiva. Com os dados no cadastro, tendo que retornar à agência do SINE de seis em seis meses, sendo que o SINE não tem preenchido, conforme dados fornecidos do SIGAE, todas as vagas de emprego que consegue captar no mês.

Em abril de 2002, o número de encaminhamentos do seguro-desemprego foi maior: 1.001, 245 vagas captadas e 153 colocações, sendo encaminhadas para essas vagas 508 pessoas.

As políticas de $1^{\circ}$ emprego para jovens se justificam inclusive quando analisamos os dados dispostos nas agências do SINE, pois, no mês de março, foram disponibilizadas apenas 15 vagas para pessoas entre 14 e 17 anos, 281 vagas para pessoas entre 18 e 29 anos, 291 para as vagas entre 30 e 39 anos, 257 vagas para as entre 40 e 49 anos. Claro que aqui se repetem as mesmas vagas diante de faixas etárias diversas. Recordando que no mês de março foram 225 vagas captadas. Nesse mês, um número significativo de vagas no setor de serviços.

Ocorreu um número considerável de mulheres empregadas via as vagas do SINE em março de 2002. Das 184 colocações nenhuma envolve jovens, 21 homens de 18 a 29 anos, para 47 mulheres; 11 homens e 54 mulheres de 30 a 39 anos, 11 homens e 31 mulheres dos 40 aos 49 anos e 3 homens e 6 mulheres com mais de 50 anos.

As vagas disponibilizadas, a maioria no setor de serviços, durante o mês de março de 2002 não exigiam escolaridade significativa, pois 183 vagas admitiam qualquer escolaridade para seu preenchimento. As vagas que admitiam mulheres exigiam grau de escolaridade maior que os homens para as primeiras serem admitidas, 29 vagas tendo como critério Ensino Médio, 22 vagas as séries iniciais da alfabetização (4 ${ }^{\mathrm{a}}$ série completa), 7 vagas exigindo o $3^{\circ}$ grau completo.

Uma das funcionárias da captação de vagas me falou que a unidade de Pelotas é responsável pela colocação de $19 \%$ a $22 \%$ das vagas da cidade, existem 4 agências de emprego privadas, uma ligada à Câmara dos Dirigentes Lojistas, sendo que as agências privadas muitas vezes recorrem ao cadastro deles para as vagas, anunciam vagas no jornal e televisão pelo SINE já que pelo SINE é gratuito, sendo que essas agências cobram um percentual no primeiro salário da pessoa quando esta conquista a vaga.

O coordenador do SINE (que se afastou do cargo ainda no primeiro semestre de 2002 para organizar a campanha política partidária para presidente, governador, senador, deputados estaduais e federais na cidade), segundo as funcionárias do setor de captação de vagas, teve uma experiência constrangedora ao visitar empresas e escutar que o SINE 
não encaminhara pessoas qualificadas para a vaga, que a empresa tivera prejuízo ao contratar pessoas selecionadas pelo SINE e precisara demitir.

Conforme depoimento de uma funcionária da intermediação, a visita às empresas não foi uma novidade instituída pelo coordenador:

"Tiveram uma equipe de rua para captação de vagas nas empresas, que visitava empresas - este serviço foi desativado, ficaram sem transporte para fazer este trabalho.

Esta equipe de rua muitas vezes ia com veículo próprio."

Um número significativo dos funcionários possuía curso superior: várias assistentes sociais, psicóloga, economista doméstica, advogado, engenheiro elétrico, jornalista; outros formados com a prática, com anos de experiência na FGTAS (Fundação Gaúcha do Trabalho e Assistência Social) a qual os funcionários das agências do SINE estão vinculados, pois o funcionário com menos tempo de serviço possuía quatro anos de FGTAS. Pelo plano de carreira da Fundação, conforme depoimento dos funcionários, as pessoas com nível superior têm salário diferenciado.

Certa vez, comentei a boa apresentação e eficiência do recepcionista para o coordenador regional, efetuei o comentário na presença do recepcionista, e a resposta do coordenador regional:

"-Por isso que ele está na portaria."

A falta de sensibilidade do coordenador regional no tratamento com os funcionários, na maioria das vezes aplicando frases feitas, diretas, como esta, em resposta ao elogio que realizei, e a delicadeza e respeito do coordenador adjunto contrastava no cotidiano da coordenadoria.

A recepção correspondia ao lugar do cuidado dos desempregados na sede do SINE. O coordenador regional do trabalho, que acumulava a coordenação do SINE de Pelotas, centralizava decisões, pensava que possuía a solução para todos os problemas na medida em que pouco consultava os funcionários e colocou na função de administração do prédio, organização dos horários e funções justamente o funcionário com menos tempo de serviço na agência da cidade e de FGTAS, pois teve transferência de Porto Alegre durante a coleta de dados - o funcionário que possuía quatro anos.

Havia um constrangimento entre os funcionários, não boicotavam a ação desse colega, mas agiam na lógica do pelo menos, até porque pelo tempo de experiência de todos, a rotina se mantinha.

O coordenador titular estabelecia um controle da ação do coordenador adjunto, que, por sua vez, criava espaços autônomos como a supervisão dos cursos do Qualificar, presença 
em eventos da cidade, representando o centro regional. Em um momento, o coordenador titular pediu que o coordenador adjunto interviesse em um conflito existente no coletivo de trabalho do bairro Navegantes, no qual ocorriam reclamações em relação ao atraso de pagamento, atuação da executora dos cursos. Essa foi uma demonstração clara de colocar o coordenador adjunto em uma situação limite, em que ele, devido ao "poder e vaidade", nas palavras de um dos funcionários, não conseguiu resolver. Nessa situação, o coordenador titular recorria à sensibilidade, à experiência política com grupos populares do coordenador adjunto.

Os próprios funcionários foram melhorando sua condição de trabalho, sem esperar pelas chefias superiores, cotizando as despesas: compraram microondas para aquecer o almoço daqueles que ficavam na agência no horário do meio - dia, espelho para o banheiro, e por fim, estavam providenciando a construção de uma churrasqueira no $1^{\circ}$ piso do prédio para seus momentos de confraternização, substituindo a churrasqueira portátil.

\section{Palavras Finais}

O SINE, em sua origem, não corresponde ao "estar" do desempregado, mas ao "estar" do emprego: SINE - Sistema Nacional de Emprego, agências públicas para disponibilizar as vagas de emprego, um lugar para o emprego, não para o desempregado. Cabe ao desempregado deslocar-se com sua carteira profissional e realizar um cadastro para verificar se sua escolarização, experiência profissional é adequada para a vaga, retornando de a cada seis meses para regularizar sua situação no cadastro.

A divulgação das vagas para os cursos do Qualificar não observava as demandas dos cadastrados, na forma como estão organizados os programas dos cursos, com preenchimento da ficha do aluno quando se tem a demanda dos cursos, não recuperando as informações do SIGAE, outrossim as proposições das Comissões Municipais de Emprego. Dessa forma, não se colocam possibilidades de envolver as pessoas que se deslocam dia após dia para o SINE.

O SIGAE é um razoável banco de dados, com a realidade dos desempregados, porém com vários problemas de operacionalidade, conforme as funcionárias que o acessavam diariamente. No entanto, mesmo diante de suas limitações, é subaproveitado. Limitações que seriam resolvidas facilmente com a escuta do Ministério do Trabalho e Emprego às agências do Sistema SINE e então conformação de ajustes ao programa.

Uma funcionária do SINE, que é assistente social, verbalizava sua angústia com os desempregados que realizavam diariamente seu cadastro na agência e não eram integrados ao mercado formal de trabalho.

Perguntas sobre as rotinas do SINE ficaram ecoando: - Por que não cuidar destas 
pessoas que vêm para o SINE sem perspectiva, por que não reuni-las e realizar atividades formativas, tais como passar vídeos falando da situação do mercado de trabalho, como se comportar em entrevistas de emprego. Há profissionais no corpo técnico do SINE que poderiam contribuir na elaboração e execução de tais atividades: psicóloga, assistente social... Alternativas de acolhimento, de cuidado das pessoas sem emprego que a este espaço se dirigem.

As "dicas" reconhecidas por um desempregado; o "esforço de algumas funcionárias para conseguir alguma coisa no computador", constam nesse depoimento de um dos funcionários da intermediação:

"Já fiz seleção de funcionários com testes, dei treinamento para domésticas, minha conversa com o desempregado dura em média 15 minutos, porque, além de colocar todos os dados na ficha, coloco no programa quando é um caso excepcional que não se enquadra nos requisitos, através do encaminhamento manual, um recurso que o programa tem que eu uso muito. Aconselho para fazer um curso de informática quando é o caso, para voltar a estudar, cuidar da aparência no dia da entrevista.'

Outro depoimento de uma pessoa da intermediação de emprego, contando sobre sua forma de preenchimento do cadastro do SIGAE, demonstra as possibilidades de envolvimento com outras questões da vida da pessoa que está à sua frente, quem sabe para conseguir emprego:

"Chegou uma menina nova para intermediação com seis filhos, falamos em ligadura e outros métodos contraceptivos. Outro dia um rapaz que mora no albergue esteve aqui bem limpinho, falou das suas qualificações e que morava no albergue porque não tinha para onde ir. Liguei para um empresário amigo meu, da época que fazia as visitas de captação de vagas, encaminhei o menino para uma vaga que ele possuía, espero que o menino tenha conseguido".

As ações possíveis, em conformidade com a ética do cuidado, seriam indicar para o Programa de Educação de Jovens e Adultos da prefeitura municipal aqueles com baixa escolaridade, cursos do Qualificar, divulgar a Instituição Comunitária de Crédito (ICC) da região sul, a rede de assistência social. Conforme Boff (1999), o modo-de-ser-cuidado estabelece uma tonalidade diferente ao trabalho: "Não existe, co-existe com todos os outros. A relação não é de domínio sobre, mas de com-vivência. Não é pura intervenção, mas inter - ação e comunhão" (p.95).

Há registos de memória dos funcionários antigos, que poderiam ser indicativos para implementação de medidas atuais:

"Em outros tempos a intermediação de emprego tinha uma assistente social para fazer o trabalho de linha de frente - há uns 10 anos, sendo vistos os vários problemas da pessoa e um atendimento individual através da psicóloga para os casos mais graves"

A Instituição Comunitária de Crédito[x] possuía como modalidades de crédito: individual, solidário e associativo, nos valores de $R \$ 200,00$ a $R \$ 5.000,00$, sendo as linhas de crédito 
capital de giro com juros de $4,7 \%$ ao mês em seis parcelas e capital fixo com juros de $4,5 \%$ ao mês em 14 parcelas. Conforme entrevista com o secretário municipal de desenvolvimento econômico, Pelotas, junto ao COREDE[xi] Sul, havia recebido $R \$$ 100.000,00 para o microcrédito. Os desempregados, ouvidos durante a pesquisa na agência do SINE, desconheciam a existência da Instituição Comunitária de Crédito, mesmo os integrantes dos Coletivos de Trabalho.

Até o final da pesquisa de campo não consegui visualizar movimentação de trabalhadores, cooperativas junto à Instituição Comunitária de Crédito. Pelo que pude perceber, ainda estavam resolvendo os trâmites burocráticos de sua legalização, relação com as organizações não-governamentais e sindicatos que compõem sua base de deliberação, definindo o gerenciamento pela prefeitura municipal e governo do Estado.

O investimento das centrais sindicais - Força Sindical e CUT - em compor agências com as funções do SINE (cadastro de desempregados, divulgação de vagas de emprego, regularização do seguro-desemprego, confecção da carteira de trabalho) talvez represente tentativas dos sindicatos em envolver o desempregado, além do emprego, nas rotinas dos atendimentos, além de disputar com as agências públicas do SINE os recursos do FAT.

O desempregado que procura o SINE, procura um emprego, mas também um lugar para ser cuidado, para ser incluído pois está com necessidades em função da interdição da ausência de trabalho com carteira assinada. Pelo que observei nas rotinas do SINE, ocorre uma passagem, o cumprimento de um ritual burocrático pelo desempregado.

Uma das funcionárias do atendimento inclusive me falou que via tanto o desempregado que procurava por um emprego, quanto o empregador que disponibilizava a vaga, como o artesão que fazia teste para tentar sua carteira no programa do artesanato gaúcho como clientes. E esse era um termo recorrente do vocabulário dos funcionários da agência de Pelotas, principalmente para tratar do desempregado da intermediação. Essa mesma funcionária me falou que gostara muito de um curso promovido há alguns anos pela FGTAS intitulado: "O Cliente é o rei".

Esse entendimento, conforme a dissertação de Mestrado de Nörnberg da Silva (2002), se distancia da ética do cuidado, que existe pela legitimidade do outro, por um estar-juntocom o outro.

O SINE, da forma como se apresenta, está para o emprego. O sujeito desempregado é abstrato, virtual, vai para um cadastro. Os relatos de alguns funcionários da intermediação sobre "dicas" que deram para os desempregados não compõem o planejamento das atividades da instituição. Elas podem ocorrer, ou podem ser substituídas pelo preenchimento rápido da ficha em dias em que porventura algum colega tenha faltado, por 
a fila estar grande, ou em função do término do horário do expediente.

Deixar na "boa vontade" do funcionário realizar uma entrevista com o desempregado que questione o local onde ele mora, quantos filhos ele tem, o tipo de relação que ele tem com o trabalho, é contar com o "acaso", com a "imprevisibilidade", podendo incorrer em relações circunstanciadas na ética do cuidado; mas também pode incorrer na apatia, na frieza, ou na rejeição pela idade, ou ainda, a certeza de não poder ocupar esse espaço, não reconhecer nele uma alternativa.

Evidentemente, o planejamento, a integração das ações por si não coadunam para a ética do cuidado com os desempregados, mas podem cuidar, a princípio, daqueles que são funcionários da instituição, no diálogo sobre suas práticas, na valorização e reconhecimento de suas ações, quem sabe na transfiguração do olhar para o desempregado para além do emprego, vislumbrando suas interações comunitárias, nos movimentos sociais, nas religiões, potencializando, assim, as formas e os resultados das políticas vinculadas aos Centros Regionais de Desenvolvimento, Trabalho e Renda, bem como a transfiguração das agências do SINE para um lugar também do desempregado.

Falta uma interpretação da vida presente nas rotinas das agências do SINE que contemple o modo-de-ser-cuidado nas relações estabelecidas pelos funcionários do SINE com os desempregados, esse local não somente como passagem burocrática, preenchimento de cadastro, mas com permanências, reconhecimentos, cuidado em relação ao desempregado.

\section{Referências Bibliográficas}

BALANDIER, Georges. O contorno: Poder e modernidade. Rio de Janeiro: Bertrand Brasil, 1997b.

BOFF, Leonardo. Saber Cuidar: ética do humano - compaixão pela terra. 3. ed., Petrópolis: Vozes, 1999.

NÖRNBERG DA SILVA, Marta. A ética do cuidado numa instituição filantrópica. Porto Alegre: UFRGS, Dissertação de Mestrado - Programa de Pós-Građuação em Educação, Faculdade de Educação, Universidade Federal do Rio Grande do Sul, Porto Alegre, 2002.

SANTOS, Simone Valdete dos. O Ser e o Estar de Luto na Luta: Educação Profissional em Tempos de Desordem - Ações e Resultados do PLANFOR / Qualificar na cidade de Pelotas/RS (2000-2002). Porto Alegre: UFRGS, Tese de Doutorado - Programa de Pós-Graduação em Educação, Faculdade de Educação, Universidade Federal do Rio Grande do Sul, Porto Alegre, 2003.

[i] Doutora em Educação, professora da Faculdade de Educação da Universidade Federal do Rio Grande do Sul, membro do Núcleo de Estudos "Educação e Gestão do Cuidado", e mail: ssantos5@terra.com.br.

[ii] A combinação que fiz com o coordenador regional de emprego, trabalho e renda (titular) foi que conversaria com todos os funcionários que quisessem, que se dispusessem dentro do horário de expediente, sem atrapalhar as rotinas de trabalho. 
[iii] Esse funcionário é negro, músico, participante de um bloco de carnaval na cidade fundado por negros.

[iv] A distância entre Capão do Leão e Pelotas é de 20 quilômetros.

[v] Tive o cuidado de observá-lo, várias vezes, sem que ele identificasse minha presença, entrando por outra porta da agência, em horários variados do início do expediente às 8 horas, encerrando às 12 horas, retornando o expediente à tarde das 13 horas e 30 minutos até às 18 horas. Eu mesma, quando a agência estava localizada no prédio alugado, presenciei sua atenção ao solicitar a presença do coordenador regional de trabalho e renda, quando ele me indicou a sala do coordenador, informou-se se ele poderia me receber, procedeu na sua função com toda a eficiência.

[vi] Balandier (1997b).

[vii] Foram beneficiados 80 jovens pelo programa $1^{\circ}$ emprego em Pelotas, estando cadastrados cerca de 500 até o final de 2002, conforme a funcionária responsável pelo programa na agência.

[viii] Há um convênio da Incubadora Tecnológica da UCPel com o SEDAI, firmado em junho de 2002, para desenvolver os projetos de economia popular e solidária, junto à coordenadoria regional de emprego, trabalho e renda da região sul. Em todos os centros regionais foram firmados convênios com as seguintes universidades: UCPel, UPF, Unisinos, UFRGS, UNISC e UNIJUÍ. Nos módulos dos Coletivos de Trabalho há tentativas de iniciativas econômicas, linhas de crédito a partir do orçamento participativo e do Banrisul no seu programa de economia popular. É disponibilizado capital de giro, maquinário usado/novo para as iniciativas vinculadas à agricultura. A disponibilização de recursos para economia popular e solidária passa pelos seguintes passos, conforme entrevista com os responsáveis em Pelotas, vinculados a UCPel:

1)Discussão todo o processo com as pessoas envolvidas nas cooperativas/associações

2)Financiamento como uma ação complementar

3) Elaboração de um diagnóstico pelos técnicos para observar o potencial do empreendimento, concorrentes, vendas

4) Possibilidade de projetos de melhoria, auto-gestão junto aos cooperados.

A experiência tem mostrado para eles que o maior problema é de gestão junto as cooperados, nem tanto é falta de recurso. A gestão é problema estadual das alternativas de economia popular e solidária.

No escritório de desenvolvimento regional da UCPel, coordenado pelo professor Claudio Gastal, está o crédito assistido, extensão empresarial (micro, pequenas, médias empresas), redes de cooperação, economia popular e solidária, comércio exterior. As macrorregiões para assessoria da UCPel foram constituídas a partir do convênio firmado com o governo do Estado: sul, campanha e fronteira oeste. A metodologia do trabalho está vinculada aos programas do Estado, a prestação de serviço ocorre em Pelotas e região, há um considerável empenho na conformação de cooperativas no meio rural.

[ix] Nas feiras populares ocorria integração pois a Secretaria de Desenvolvimento Econômico organizava as feiras, como já foi mencionado no capítulo anterior, e um setor da coordenadoria legalizava o ofício de artesão, garantia a presença do artesão na feira, pois fornecia uma carteira, podendo esse emitir nota fiscal, regularizar sua atividade econômica e profissional Essa formalização ocorria após a análise do processo de trabalho, materiais utilizados e produto, por uma funcionária responsável na sede do SINE, atividade inserida no "Programa do Artesanato Gaúcho" implementado pela gestão de Olívio Dutra, que regularizou a profissão de artesão.

[x] Sob a coordenação da Secretaria do Desenvolvimento e dos Assuntos Internacionais (SEDAI), a gestão do Governo Olívio Dutra implementou Instituições Comunitárias de Crédito nas seguintes regiões do Estado: região da Serra com sede na cidade de Caxias do Sul, região da Campanha em Bagé, região sul em Pelotas, região Médio/Alto Uruguai e Celeiro em Frederico Westphalen e Banco do Povo da Região Central, em Santa Maria.

[xi] Conselho Regional de Desenvolvimento.

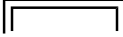


volta

file://C:|Documents and Settings\AdministradorlMeus documentos\Minhas Webs\NED... 11/9/2008 